\title{
Roger 3450 Vs RF4 Martials - Based Frequency And Pattern Reconfigurable Rectangular Patch Slot Antennas For RFID Applications
}

\author{
Salah Mohmad Alsadiq Aboghsesa ${ }^{1}$, Adam Amril Jaharadak ${ }^{2}$, Falah Y H Ahmed ${ }^{3}$ \\ ${ }^{1,2}$ School of Graduate studies [SGS], Management Science University, 40100 Shah Alam, Selangor, Malaysia \\ ${ }^{3}$ Faculty of Information Sciences and Engineering, Management and Science University, \\ 40100 Shah Alam, Selangor, Malaysia \\ salahmohmad1978@gmail.com, adam@msu.edu.my, falah_ahmed@msu.edu.my
}

Article History: Received: 11 January 2021; Accepted: 27 February 2021; Published online: 5 April 2021

\begin{abstract}
Rectangular Patch Slot Antennas RPSA are getting becoming more likable and popular for practice in wireless implementations such as RFID applications especially in the UHF band thanks to its low-profile structure. This kind of antenna is able to deliver large communication distances but this antenna coverage is very weak which is part of the main drawbacks of these antennas. In this paper, Rectangular Patch Slot Antenna RPSA with different slots has been designed and simulated to be suitable for RFID applications. Circular polarized CP antenna that has been designed to use feed structure with vertical ground encircling a radiating component. The feeding method to feed this antenna is coaxial probe. The paper will concentration on both substrate materials Roger 4350 and FR4 Glass-Epoxy material to model and simulate the designs. The other factor of the design is the patch antenna will cut at the four truncated corners to enhance the antenna gain which will affect considerably the operating frequency. This paper aims to show and find the best feed point area that has an exceptional antenna return loss (S11) and high gain. S11 describe the power reflected from the antenna, which is known as the reflection coefficient S11 must be $\leq-10 \mathrm{~dB}$. The design and simulation results of RPSA has been done by high frequency simulation system (HFSS 13.0).
\end{abstract}

Keywords: Rectangular Patch Antenna RPA, Rectangular Patch Slot Antenna RPSA, Feed line technical, Circular Polarized CP and RFID technology, Substrate Materials Roger 4350 and FR4 Glass-Epoxy.

\section{Introduction}

Nowadays, Information and Communication Technology ICT development and delivery a lot of various of networks technologies and their application such as antenna systems which are widely use today such as satellite, radio frequency Identification RFID[1], radio frequency RF and communication networking system and even at health care. There are many types of antennas which play a vital role in communication technology which is Micro-Strip Patch Antenna MSPA one of them but the primary concern type in this paper is Micro-Strip Patch MSPA antenna. MSPAs have different shapes for different applications and one of these shapes is Rectangular Patch Antennas RPA which will be suitable for RFID applications. RPA with radio frequency Identification RFID are getting slenderer and more brilliant [2] and [1]. RPA and Rectangular Patch Slot Antenna RPSA are prevalent reproduced tuned antennas for wireless scheme of RFID. RPA systems are playing an imperative part in mobile communication systems due to their numerous gains such as weightless, less complexity contour, low cost it delivers simplicity in integration in communication devices and cost efficiency [2] and [3]. The main concentration of this paper will be on a RPSA integrated design modelling novelty devoted entirely for mainly RFID applications with optimized Return Loss (S11) and total antenna gain performance[4]. However, to model and simulate RPA and RPSA antenna systems by employing HFSS simulation environments with few design techniques that would present higher gain than other counterparts which will offer high sensitivity and better antenna pattern that would be applied for RFID applications effectively and efficiently.

\section{Circular polarized CP}

Circular polarized $\mathrm{CP}$ antenna that has been designed to use feed structure with vertical ground surrounding a radiating element[5]. A High Frequency Structure Simulator (HFFS) was used to model, analyze and simulate of $\mathrm{CP}$ antenna[6]. The specifics of the modeled CP of antenna model are qualified, and the outcomes of simulated are offered and debated. A circular polarized (CP) antenna is modeled to employ a simple feed structure together vertical ground surrounding a radiating element and compared to the author's model [7]. The Circularly polarized (CP) rectangular antenna with perpendicular surface utilized mainly for reader applications for RFID will be delivered. The structural assembly of the intended and projected antenna consists of a patch that has the capability of radiating electromagnetic waves[8]. The radiation of EM waves will be directed on a substrate besides a perpendicular ground adjoining four borders of the antenna. The resonant operating frequency will be reduced with an amount can reach up to $25 \%$ due to the effects of the vertical ground influences. This amount can be 
compared and contrasted relatively to that antenna that has no vertical ground or perpendicular surface [9].

\section{RFID technology and applications}

The RFID technology has revolutionized the supply chain management industry as it avoids overstocking difficulties [10]. Radio Frequency Identification (RFID) are one of the most solutions to such capacity[11]. Previously, there were an affordable technology namely printed label. These labels are less costly technology however they are not efficient for mass production in the manufacturing industry. The earlier identification process was standardized in the 1970s using barcodes, [10] and [12] for example, the producer and item sequential number. And other example, "Healthcare of alternative solutions have been have been pointing out as a viable approach to ameliorate the increasing demand for telehealth and prompt healthcare delivery [13]. Initiated system apply RFID tags placed at different positions at target of body. RFID frameworks are proficient to distinguish different kinds of labels situated in any territory with less collaboration with individual's contribution[14].

\section{Related work}

One of studies were carried out in 2018 on same study design using RF4 [5] were optimization value S11 $20 \mathrm{~dB}$ and gain from 2.0 to $3.0 \mathrm{dBi}$. At other hand, [6] proposed a compact meandered cross-shaped slot circularly polarized antenna suitable for the range of ultra-high frequency (UHF). The S11 $=-13$ and $-16 \mathrm{~dB}$ as displayed in Figure 5. In other research project, [7] the authors designed the dual band coupled resonators band pass filter that uses two $\mathrm{C}$ shaped defected ground structures (DGSs)Dual band wireless power transfer (DB-WPT) applications. S11 value of $-22 \mathrm{~dB}$ has been obtained. [8] has tested one main radiation patch and one parasitic radiation patch with air as the dielectric used for UHF RFID. S11 values was $-33 \mathrm{~dB}$ as be noticed in at frequency of $0.85 \mathrm{GHz}$. In a relevance to paper, (Patel, 2019), Low profile multiband meander antenna for LTE/WiMAX/WLAN and INSATC Application LTE (FDDTDD)/ WLAN and INSAT C-Band TX (Transmit) frequency has been proposed. A project paper [6], recommended Meandered Cross-shaped Slot Circularly Polarized Antenna for Handheld UHF RFID Reader compact meandered cross-shaped slot circularly polarized antenna for (UHF) Wireless and UHF RFID applications. According to paper [9], studied Performance analysis of rectangular MSPA for wireless application using FPGA. This research applied RT/duriod 5880 material is used as the substrate and coaxial probe feed method is used to gives the excitation value of the antenna, antenna gain[15].

\section{Mythology of design Rectangular Patch slot Antenna RPSA}

Research methodology applied on the design approaches on major topic of RPA and RPSA with four corner slots which will test in both Roger 4350 and FR4 Glass-Epoxy substrate martials[16]. This paper research work features the planning, the designing and configuring of a Rectangular Patch slot Antenna RPSA which relies upon the three principal factors identified by the following the frequency of operation, thickness of the utilized substrates, and the dielectric coefficient of substrates. [17].Figure 2. It starts with design specification is identified by determining and calculating the dimensions of the patch slot antenna. Antennas geometrical and the material are properly defined by select Roger Ro 3450 and the ground plane was printed in another face side of the substrate with dimensions of $50 \mathrm{~mm} \times 50 \mathrm{~mm}$. Then move to design the Patch Antenna which is printed on a Roger Ro4350 material $30 \mathrm{~mm} \times 40 \mathrm{~mm}$ of relative permittivity $\varepsilon_{\mathrm{r}}=3.66$ and of loss tangent of 0.004 . The substrate thickness is $0.8 \mathrm{~mm}$. The radiator is fed by coaxial probe inserted at middle of the antenna patch [18]. After that, parametric models will be assigned. This assignment will include boundaries and exclusions Paramedic mode, will guide towards analysis as a solution set up as well as frequency sweep. Then, in terms of analysis, the simulation is carried out using HFSS. HFSS will attempt to test the design if the optimum results did not occur then it will perform feedback to antennas geometrical (Cutting slots technique with $5 \mathrm{~mm}$ at each corner) and select the other material to design refinements. If design refinements will be performed well and undergone to solve and converge steps successfully, then it will lead to positive step which is 'Yes' status. Beyond this step is the finishing step. Now, the fabrication process begins after the simulations result are Optimized. At the end steps, the fabricated antenna is measured to validate the simulation result and verify the technical specifications. End.

reached $6.1 \mathrm{dBi}$ and S11 was around $14 \mathrm{~dB}$. 


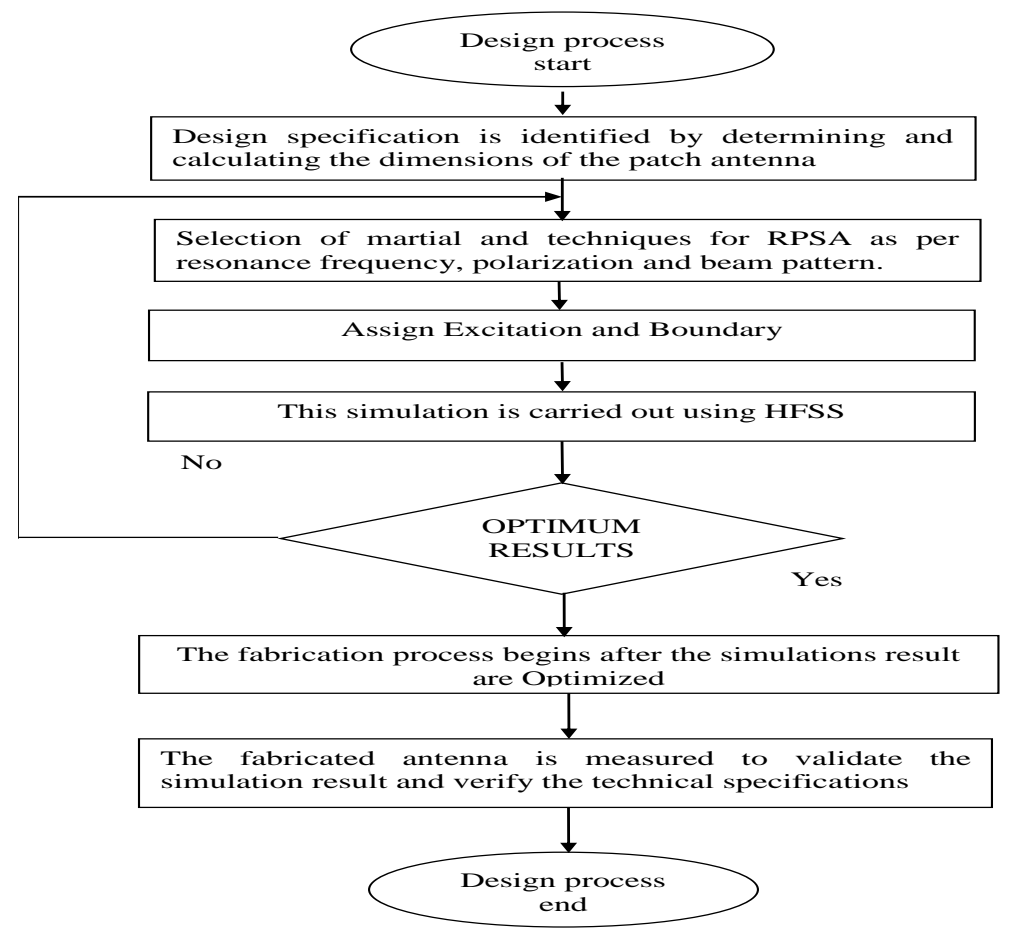

Fig. 2. Flow Chart of HFSS deployment illustrating the design and modelling processes.

6.

Result of hybrid (Antenna1) with two slots Ro4350 material

The patch is printed on a Roger Ro4350 material $30 \mathrm{~mm} \times 40 \mathrm{~mm}$ of relative permittivity $\quad \varepsilon r=3.66$ and of loss tangent of 0.004 . The substrate thickness is $0.8 \mathrm{~mm}$. The radiator is fed by coaxial probe inserted in the middle of the patch as indicated in Figure 2. The ground plane is printed in another side of the substrate with dimensions of $50 \mathrm{~mm} \times 50 \mathrm{~mm}$. The now patch design was cut at the two truncated corners to enhance the antenna gain of a couple of reverse shortened angles with the value $\mathrm{C}=5 \mathrm{~mm}$ in Figure 3 .

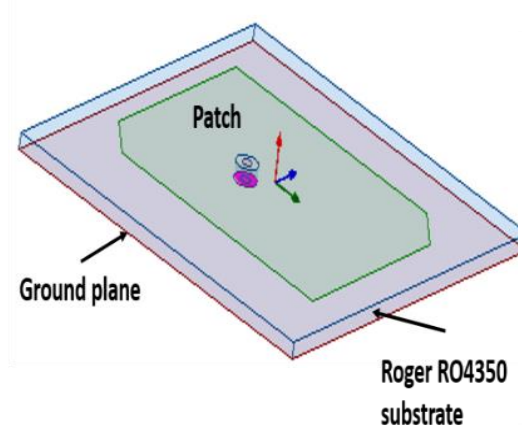

(a)

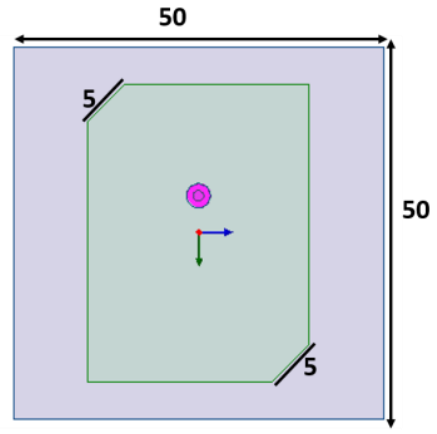

(b)

Fig. 3. Design of Antenna 3, (a) front view, (b) 3D view, Unit in mm

\section{7. $\quad$ RPSA Reflection Coefficient S11}

Rectangular Patch Slot Antenna (RPSA) with two slots has been measurement and designed at operating frequency $1.9 \mathrm{GHz}$ with input impedance $50 \Omega$. The simulated resulting of antenna design shows that the value of return loss (S11) has value -20 dB. The graph at Figure 4 shown the value of S11of proposed Antenna 1. 


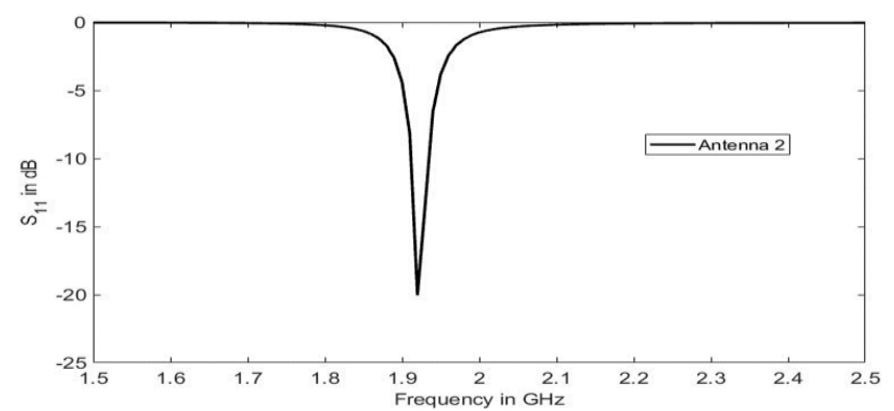

Fig. 4. Return loss of proposed Antenna 1 (Roger Substrate)

\section{Gain}

RPSA antenna four slots has obtained of result of power gain the value $6.1 \mathrm{dBi}$ with Roger substrate at operating frequency $1.9 \mathrm{GHz}$ the graph at Figure 5 shown power gains result of proposed Antenna 1.

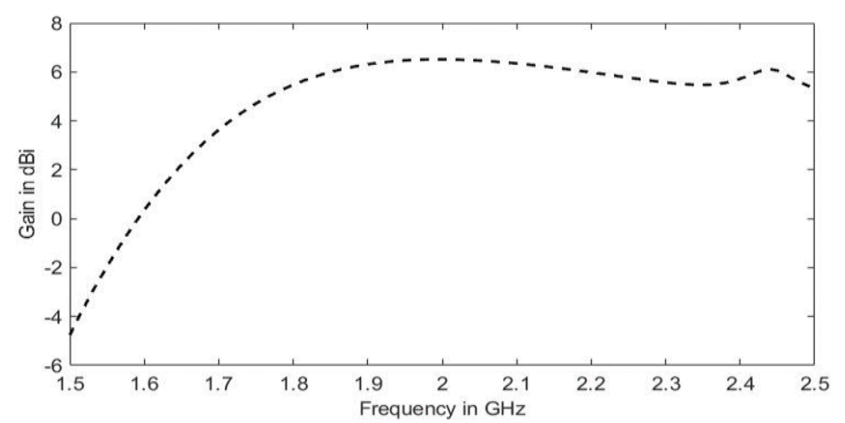

Fig. 5. The power gains of proposed Antenna 1 (Roger Substrate)

\section{Radiation pattern}

The schema of the radiating patterns is to show that the Rectangular Patch Slots Antenna (RPSA) actually radiates at operating frequency $1.9 \mathrm{GHz}$ band. It can be seen that the radiation patterns in $\mathrm{x}-\mathrm{z}$ plane are almost Omnidirectional as shown in Figure.6
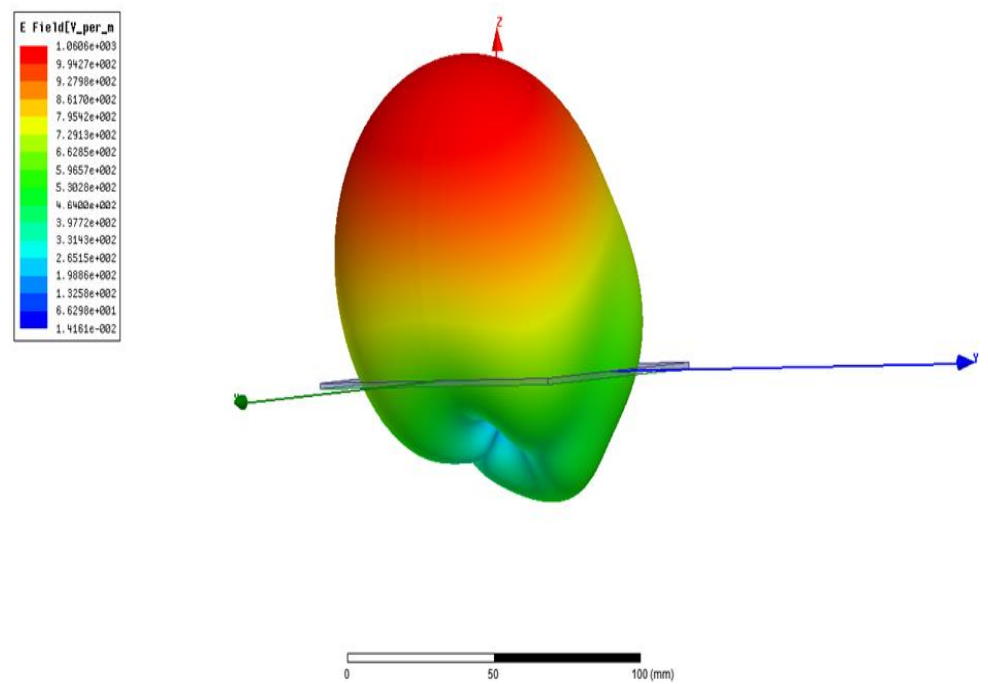

Fig. 6. Antenna (Roger Substrate) radiation patterns Omni-directional 


\section{Result of hybrid (Antenna 2) with two slots FR4 Substrate material}

The antenna geometry is given in Figure7 the patch is printed on an FR4 material of relative permittivity $\varepsilon_{\mathrm{r}}=4.4$ and of loss tangent of 0.017 . The substrate thickness is $0.8 \mathrm{~mm}$. The radiator is fed by coaxial probe inserted in the middle of the patch as indicated in Figure1. The ground plane is printed in another side of the substrate with dimensions of $50 \mathrm{~mm} \times 50 \mathrm{~mm}$. The patch antenna is printed in side substrata with dimensions of $40 \mathrm{~mm} \times 30 \mathrm{~mm}$ meanwhile the ground plane is printed in another side of the substrate. The feeding method to feed this antenna is coaxial probe. The now patch design was a cut at two corners with the value $5 \mathrm{~mm}$ to enhance the antenna gain of a couple of reverse shortened angles as shown in Figure 7.

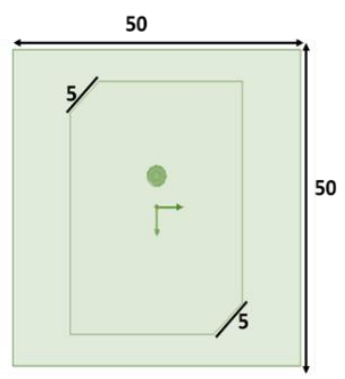

(b)

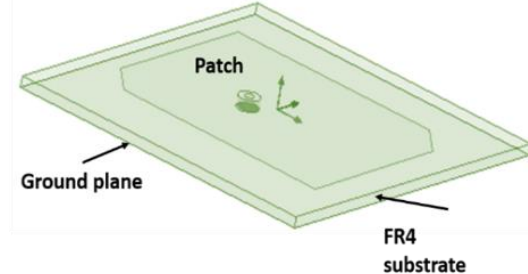

(a)

Fig. 7. Design of Antenna 3 (FR4 Substrate), (a) front view, (b) 3D view, Unit in mm

\section{Reflection Coefficient S11}

The Rectangular Patch Slot Antenna RPSA with RF4 substrate martial has presented poor value of return loss (S11) which is $-7.1 \mathrm{~dB}$ at operating frequency $1.75 \mathrm{GHz}$ which not acceptable since that the acceptable level must be $\mathrm{S} 11 \leq-10 \mathrm{~dB}$ with input impedance $21 \Omega$ the Figure. 8 shown return loss and the input impedance, real and imaginary of proposed Antenna 2.

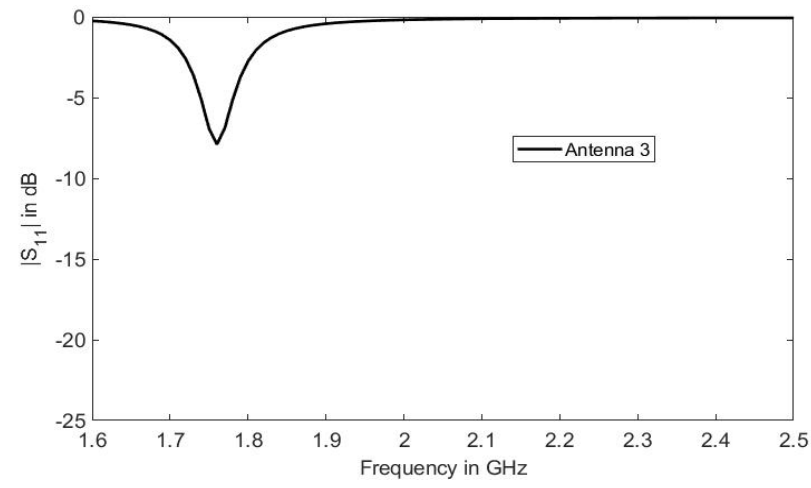

Fig. 8. Return loss of proposed Antenna 3 (FR4 Substrate)

\section{Gain}

Figure 9 shown the obtained results of power gains $1.6 \mathrm{dBi}$ of RPSA antennas with RF4 substrate at operating frequency $1.76 \mathrm{GHz}$. 


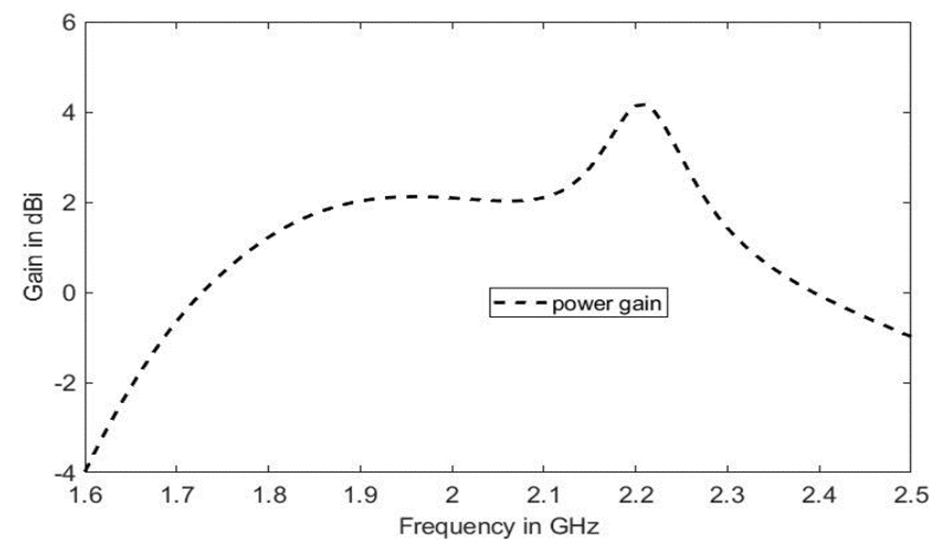

Fig. 9. The power gains of proposed Antenna 3 (FR4 Substrate)

\section{Radiation pattern}

Radiation pattern of the Rectangular patch Slots antenna RPSA (FR4 Substrate) at operating frequency $1.76 \mathrm{GHz}$. The direction of RPSA is Omni-directional as shown in Figure 10.

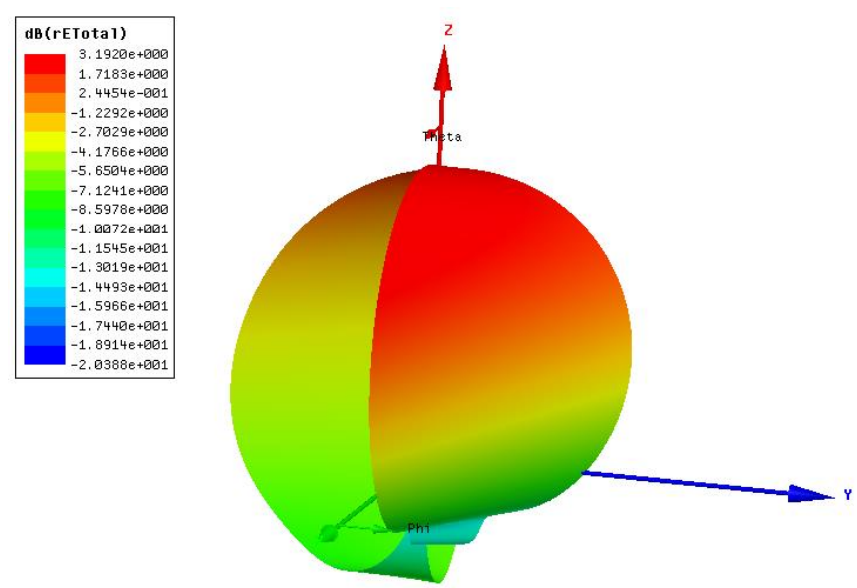

Fig. 10. Radiation pattern RPSA (FR4 Substrate).

14. Comparison results between Rectangular patch Slots antenna RPSA slot Ro 3450 and Rectangular patch Slots antenna RPSA with FR4 shown in table.1 below

Table 1. Comparison RPSA with Ro 3450 material and RPSA with FR4 material

\begin{tabular}{|c|c|c|}
\hline Parameters & RPSA slots Ro 3450 material & RPSA slots FR4 material \\
\hline Operating frequency & $1.9 \mathrm{GHz}$ & $1.75 \mathrm{GHz}$ \\
\hline Bandwidth & $350 \mathrm{MHz}$ & $300 \mathrm{MHz}$ \\
\hline Return loss & $20 \mathrm{~dB}$ & $7.1 \mathrm{~dB}$ \\
\hline Gain & $6.1 \mathrm{dBi}$ & $1.5 \mathrm{dBi}$ \\
\hline Input impedance & $50 \Omega$ & $21 \Omega$ \\
\hline Radiation pattern & Omni-directional & Omni-directional \\
\hline
\end{tabular}

15. Conclusion

From the obtained results the antennas with Roger Ro 4350 substrate have indicated better performance in particular in terms of return loss, impedance matching and power gains. The last test design was RPSA with FR4 
antenna has presented poor value of return loss (S11) which is-7.1dB at operating frequency $1.75 \mathrm{GHz}$ which not acceptable since that the acceptable level must be $\mathrm{S} 11 \leq-10 \mathrm{~dB}$. The design and analysis antennas with Roger 4350 with tests results was successful. The design has good performance regarding to the value of return loss RL which is referred to S11. S11vlue $20 \mathrm{~dB}$. RPSA with Roger 4350 substrate material has good performance compared to RPSA FR4 substrate material.

\section{References}

1. M. B. Eunni, “A novel planar microstrip antenna design for UHF RFID," Madhuri Eunni-Master's Thesis Def., vol. 19, 2006.

2. A. Pandey and R. Mishra, "Compact Dual Band Monopole Antenna for RFID and WLAN Applications," Mater. Today Proc., vol. 5, no. 1, pp. 403-407, 2018.

3. A. Iqbal et al., "Electromagnetic bandgap backed millimeter-wave MIMO antenna for wearable applications," IEEE Access, vol. 7, pp. 111135-111144, 2019.

4. J.-S. Sun and C.-H. Wu, "A broadband circularly polarized antenna of square-ring patch for UHF RFID reader applications," AEU-International J. Electron. Commun., vol. 85, pp. 84-90, 2018.

5. I. T. Elfergani, J. Rodriguez, I. Otung, W. Mshwat, and R. A. Abd-Alhameed, "Slotted Printed Monopole UWB Antennas with Tuneable Rejection Bands for WLAN/WiMAX and X-Band Coexistence,” 2018.

6. A. Mehta, "Microstrip antenna,” Int. J. Sci. Technol. Res., vol. 4, no. 3, pp. 54-57, 2015.

7. R. Patel, T. Upadhyaya, A. Desai, and M. Palandoken, "Low Profile Multiband Meander Antenna for LTE/WiMAX/WLAN and INSAT-C Application," AEU-International J. Electron. Commun., vol. 102, pp. 90-98, 2019.

8. Y. Li and W. Yu, "A miniaturized triple band monopole antenna for WLAN and WiMAX applications," Int. J. Antennas Propag., vol. 2015, 2015.

9. S. Pyo and Y. Sung, "Asymmetrical coupling feed of circularly polarized microstrip antenna for bandwidth enhancement," Microw. Opt. Technol. Lett., vol. 58, no. 7, pp. 1672-1675, 2016.

10. T. Kaufmann, D. C. Ranasinghe, M. Zhou, and C. Fumeaux, "Wearable quarter-wave folded microstrip antenna for passive UHF RFID applications," Int. J. Antennas Propag., vol. 2013, 2013.

11. N. Kalambe, D. Thakur, and S. Paul, "Review of microstrip patch antenna using UWB for wireless communication devices," Int. J. Comput. Sci. Mob. Comput., vol. 4, no. 1, pp. 128-133, 2015.

12. [N. Sharma and V. Sharma, "A design of Microstrip Patch Antenna using hybrid fractal slot for wideband applications," Ain Shams Eng. J., vol. 9, no. 4, pp. 2491-2497, 2018.

13. S. M. Aboghsesa, N. Daud, and T. M. Abdala, Analysis and Simulation of Slottede ALOHA-based RFID Anti-collision Protocol. 2015.

14. S. Bhaskar and A. K. Singh, "Meandered cross-shaped slot circularly polarised antenna for handheld UHF RFID reader,” AEU-International J. Electron. Commun., vol. 100, pp. 106-113, 2019.

15. M. S. R. Bashri, M. I. Ibrahimy, and S. M. A. Motakabber, "A planar wideband microstrip patch antenna for UHF RFID tag," in 2013 IEEE International Conference on Space Science and Communication (IconSpace), 2013, pp. 302-306.

16. N. Sabbar, K. Hati, H. Asselman, and A. El Hajjaji, "A new monopole antenna in the form of double dollar-symbol for WLAN (5.1-6 GHz) applications," Procedia Manuf., vol. 22, pp. 539-544, 2018.

17. S. M. A. Aboghsesa, A. A. Jaharadak, and F. Y. H. Ahmed, "Analysis and Design of Rectangular MicroStrip Patch Antennas for (RFID) Applications Using HFSS 13.0,” Solid State Technol., vol. 63, no. 1, pp. 53-63, 2020.

18. K. Wong, Broadband, vol. 3. 2002. 